\title{
Realgar induces apoptosis in the chronic lymphocytic leukemia cell line MEC-1
}

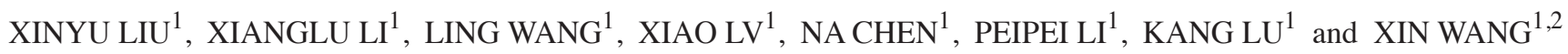 \\ ${ }^{1}$ Department of Hematology, Provincial Hospital Affiliated to Shandong University, Jinan, Shandong 250021; \\ ${ }^{2}$ Institute of Diagnostics, Shandong University, Jinan, Shandong 250012, P.R. China
}

Received April 25, 2013; Accepted October 8, 2013

DOI: $10.3892 / \mathrm{mmr} .2013 .1731$

\begin{abstract}
The aim of the present study was to investigate the effect of realgar on the viability, proliferation and apoptosis in the human chronic lymphocytic leukemia (CLL) cell line, MEC-1. Potential mechanisms mediating the effect were also explored in the experiment. Cultured MEC-1 cells were incubated with various concentrations of realgar for 24, 48 and $72 \mathrm{~h}$. A WST- 8 assay was employed to evaluate the effect on cell viability. Inhibitory effects on cell proliferation were determined using a 5-bromodeoxyuridine cell proliferation ELISA. The apoptotic effect on MEC-1 cells was evaluated by annexin V-fluorescein isothiocyanate/propidium iodide dual staining, followed by flow cytometry. Quantitative polymerase chain reaction was performed to determine the mRNA expression levels of BCL2-associated X protein $(B A X)$, BCL2-like $1(B c l-x L)$, v-myc myelocytomatosis viral oncogene homolog (avian; $c-M y c)$ and cyclin-dependent kinase inhibitor 1A ( $p 21)$. It was found that viability and proliferation were significantly reduced while apoptotic rates increased in MEC-1 cells following exposure to realgar. Furthermore, mRNA expression of $B A X$ and $c-M y c$ was upregulated and downregulated, respectively, in realgar-treated MEC-1 cells. In conclusion, the results showed that realgar inhibits viability and proliferation and induces apoptosis of MEC- 1 cells in a dose- and time-dependent manner. The effect may depend on the mitochondrial apoptosis pathway. The results of the present study
\end{abstract}

Correspondence to: Professor Xin Wang, Department of Hematology, Provincial Hospital Affiliated to Shandong University, 324 Jingwu Road, Jinan, Shandong 250021, P.R. China

E-mail: xinwang55@yahoo.com.cn

Abbreviations: TCM, traditional Chinese medicine; $\mathrm{As}_{2} \mathrm{O}_{3}$, arsenic trioxide; APL, acute promyelocytic leukemia; $\mathrm{As}_{2} \mathrm{~S}_{2}$, realgar, arsenic sulfide; CML, chronic myelogenous leukemia; CLL, chronic lymphocytic leukemia; IMDM, Iscove's modified Dulbecco's medium; $\mathrm{IC}_{50}$, inhibitory concentration of $50 \%$; BrdU, 5-bromodeoxyuridine; FITC, fluorescein isothiocyanate; PI, propidium iodide; cDNA, complementary DNA

Key words: chronic lymphocytic leukemia, realgar, apoptosis may be beneficial in the identification of a new target therapy for CLL.

\section{Introduction}

Traditional Chinese medicine (TCM) has been used as effective antitumor agents for numerous years in ancient China (1). However, it is difficult to identify the active ingredient due to the complex composition. Thus, the use of TCM has been severely restricted in clinical practices following the introduction of western antineoplastic methods, including radiotherapy and chemotherapy. The therapeutic efficacy of arsenic trioxide $\left(\mathrm{As}_{2} \mathrm{O}_{3}\right)$ has been shown previously in the treatment of acute promyelocytic leukemia (APL), of which the mechanism has also been identified (2-6). Consequently, TCM has become an important area of study again and attracted considerable attention in aspects of cancer treatment, particularly in the treatment of malignant hematologic diseases. Numerous studies have been conducted thus far, yielding a number of achievements (7-11).

$\mathrm{As}_{2} \mathrm{O}_{3}$ and realgar (arsenic sulfide, $\mathrm{As}_{2} \mathrm{~S}_{2}$ ) belong to a group of Chinese arsenic drugs (12) and have a number of similarities. For example, realgar and $\mathrm{As}_{2} \mathrm{O}_{3}$ exhibit a good antitumor effect. Realgar is the principal constituent in the Realgar-Indigo naturalis formula (RIF), together with Indigo naturalis, Salvia miltiorrhiza and Radix Pseudostellariae. RIF shows satisfactory efficacy in treating human APL (13). Realgar has also been shown to induce apoptosis of chronic myelogenous leukemia (CML) cells through the degradation of $B C R-A B L(14,15)$. Results of recent studies have shown that $\mathrm{As}_{2} \mathrm{O}_{3}$ induced apoptosis of chronic lymphocytic leukemia (CLL) cells $(16,17)$. This effect on CLL cells may be mediated by suppressing the phosphoinositide 3-kinase/Akt survival pathway via c-jun- $\mathrm{NH}_{2}$ terminal kinase activation and PTEN upregulation (17). However, whether realgar induces apoptosis of CLL cells remains unknown.

CLL is the most common adult leukemia in western countries. It is a highly heterogeneous disease. Immunoglobulin heavy chain variable mutation status, cytogenetic changes and expression of CD38 and ZAP-70 differ among patients. Although the survival rate of CLL has improved over the past decade, with the exception of allogeneic bone marrow transplantation, no treatment is sufficiently effective to completely cure the disease. Particularly for CLL with a $17 \mathrm{p}$ deletion, 
it is almost impossible to avoid deterioration. Therefore, the purpose of the present study was to investigate the effect of realgar on the viability, proliferation and apoptosis of the human $p 53^{\text {deleted/mutated }}$ CLL cell line, MEC-1. In addition, the potential mechanism mediating the effect were explored during the study.

\section{Materials and methods}

Cell lines. Human $p 53^{\text {deleted/mutated }}$ CLL cell line, MEC-1, was suspended in Iscove's modified Dulbecco's medium (IMDM; HyClone Laboratories, Inc., Logan, UT, USA) containing $10 \%$ fetal bovine serum (HyClone), $100 \mathrm{U} / \mathrm{ml}$ penicillin and $100 \mu \mathrm{g} / \mathrm{ml}$ streptomycin. Culturing conditions were maintained at $37^{\circ} \mathrm{C}$ in a humidified atmosphere containing $5 \% \mathrm{CO}_{2}$.

Reagents. Realgar (purity, 99.53\%) was purchased from Alfa Aesar (Ward Hill, MA, USA). It was dissolved in 0.1 M sodium hydroxide and the $\mathrm{pH}$ was adjusted to 7.35-7.45 using hydrochloric acid $(14,18)$. The stock solution $\left(1 \mathrm{mM} \mathrm{As}_{2} \mathrm{~S}_{2}\right)$ was then passed through a $0.22 \mu \mathrm{m}$ filter. IMDM was used to dilute the solution prior to cell application.

Cell viability assay. A WST-8 assay kit (Beyotime Institute of Biotechnology, Jiangsu, China) was employed to evaluate the effect of realgar on cell viability. Logarithmically growing MEC-1 cells were seeded in a 96-well plate at a density of $1 \times 10^{4}$ cells $/ 100 \mu \mathrm{l} /$ well. The cells were incubated with increasing concentrations of realgar $(0,2,4,6,8,10$ and $20 \mu \mathrm{M}$ ) for 24, 48 and $72 \mathrm{~h}$. Subsequently, $10 \mu \mathrm{l}$ WST-8 was added to each well and the cells were incubated for $4 \mathrm{~h}$ prior to cell viability measurements of absorbance at $450 \mathrm{~nm}$. The inhibitory concentration of $50 \%$ of cells $\left(\mathrm{IC}_{50}\right)$ was obtained using the probit regression analysis method. Three replicates were established for each sample.

5-Bromodeoxyuridine (BrdU) cell proliferation assay. A BrdU cell proliferation ELISA kit (Roche Diagnostics Co., Indianapolis, IN, USA) was used to evaluate the inhibitory effects of realgar on cell proliferation, according to the manufacturer's instructions. MEC-1 cells with a density of $1 \times 10^{4}$ cells $/ \mathrm{ml}$ were exposed to various concentrations $(0,2$, 6 and $10 \mu \mathrm{M})$ of realgar for 24 and $48 \mathrm{~h}$. BrdU (10 $\mu \mathrm{l} /$ well $)$ was then added. Following incubation for an additional $2 \mathrm{~h}$, the culture medium was removed and the cells were fixed. Following incubation with the antiBrdU-peroxidase for $1 \mathrm{~h}$ and the substrate reaction, $25 \mu \mathrm{l}$ of $1 \mathrm{M} \mathrm{H}_{2} \mathrm{SO}_{4}$ was applied and the absorbance was read on an ELISA reader at $450 \mathrm{~nm}$.

Annexin V-fluorescein isothiocyanate (FITC)/propidium iodide (PI) dual staining. Induction of apoptosis was assessed using an annexin V-FITC apoptosis detection kit (KeyGen Biotech Co., Ltd., Nanjing, China). MEC-1 cells were treated with $0,2,6$ and $10 \mu \mathrm{M}$ realgar. Dual staining with annexin V-FITC and PI was performed, according to the manufacturer's instructions. Following incubation for 24, 48 or $72 \mathrm{~h}, 5-10 \times 10^{5}$ cells were collected, washed with PBS, stained with annexin V-FITC/PI and incubated for $10 \mathrm{~min}$ prior to analysis with a flow cytometer (Becton-Dickinson, San Jose, CA, USA). The data obtained were processed
Table I. Primers used for quantitative PCR.

\begin{tabular}{llc}
\hline Name & \multicolumn{1}{c}{ Primer sequence $\left(5^{\prime} \rightarrow 3^{\prime}\right)$} & $\begin{array}{c}\text { Product } \\
(\mathrm{bp})\end{array}$ \\
\hline Actin & F: TGACGTGGACATCCGCAAAG & 205 \\
& R: CTGGAAGGTGGACAGCGAGG & \\
$B A X$ & F: CCCGAGAGGTCTTTTCCGAG & 155 \\
& R: CCAGCCCATGATGGTTCTGAT & \\
$B c l-x L$ & F: TCAGAGCTTTGAGCAGGTAG & 182 \\
& R: AAGGCTCTAGGTGGTCATTC & \\
$c-M y c$ & F: GGCTCCTGGCAAAAGGTCA & 113 \\
& R: AGTTGTGCTGATGTGTGGAGA & \\
$p 21$ & F: CGATGGAACTTCGACTTTGTCA & 220 \\
& R: GCACAAGGGTACAAGACAGTG & \\
\end{tabular}

$\mathrm{PCR}$, polymerase chain reaction; $\mathrm{F}$, forward; $\mathrm{R}$, reverse. $B A X$, BCL2associated X protein; $B c l-x L$, BCL2-like $1 ; c-M y c, \mathrm{v}-$ myc myelocytomatosis viral oncogene homolog (avian); $p 21$, cyclin-dependent kinase inhibitor $1 \mathrm{~A}$.

with FlowJo 7.6 software (TreeStar, Inc., Ashland, OR, USA). Annexin V-FITC- and PI-negative cells were identified as viable cells. Cells with annexin V-FITC-positive and PI-negative staining were considered to be early apoptotic cells while those with annexin V-FITC- and PI-positive staining were late apoptotic cells. The addition of early and late apoptotic cells constituted the apoptotic cells.

Gene expression study by quantitative polymerase chain reaction (PCR). Transcriptional levels of BCL2-associated X protein $(B A X)$, BCL2-like $1(B c l-x L)$, v-myc myelocytomatosis viral oncogene homolog (avian; $c-M y c$ ) and cyclin-dependent kinase inhibitor 1A $(p 21)$ genes, in realgar-treated and untreated MEC-1 cells, were evaluated by quantitative PCR. Total RNA was extracted by TRIzol reagent (Invitrogen Life Technologies, Carlsbad, CA, USA) from MEC-1 cells following incubation with 0 and $6 \mu \mathrm{M}$ realgar for $48 \mathrm{~h}$. Reverse transcription to complementary DNA (cDNA) was performed using PrimeScript RT reagent kit with gDNA eraser (Takara Biotechnology Co., Ltd., Dalian, China). Quantitative PCR for the aforementioned genes was performed using a SYBR Premix Ex Taq II (Tli RNase H Plus) kit (Takara Biotechnology Co., Ltd.) on a Roche LightCycler 480 (Roche Diagnostics Co.). Actin was used as an internal control. The sequences of the quantitative PCR primers are listed in Table I. Isolation of RNA, reverse transcription and quantitative PCR were performed following the manufacturer's instructions. For data analysis the $2^{-\Delta \Delta \mathrm{Ct}}$ method was used with the following equations: $\Delta \mathrm{Ct}=\mathrm{Ct}$ (target gene) - $\mathrm{Ct}$ (actin); $\Delta \Delta \mathrm{Ct}=\Delta \mathrm{Ct}$ (realgar-treated cells) - $\Delta \mathrm{Ct}$ (untreated control). Quantitative PCR for each gene of each cDNA sample was assayed in triplicate.

Statistical analysis. Statistical analysis was performed using SPSS 17.0 (SPSS, Inc., Chicago, IL, USA). Data are expressed 
as mean $\pm \mathrm{SD}$. The significance of differences between groups was determined using the Student's t-test or ANOVA. $\mathrm{P}<0.05$ was considered to indicate a statistically significant difference.

\section{Results}

Realgar suppresses the viability of MEC-1 cells. The effect of realgar on cell viability of MEC-1 cells was evaluated using a WST- 8 assay. The MEC- 1 cells were incubated with various doses of realgar $(0,2,4,6,8,10$ and $20 \mu \mathrm{M})$ for the time periods 24, 48 and $72 \mathrm{~h}$. As shown in Fig. 1, treatment with $2 \mu \mathrm{M}$ realgar for $24 \mathrm{~h}$ resulted in a $6.80 \pm 0.70 \%$ reduction of viable cells $(\mathrm{P}<0.01)$ compared with the control group. The inhibitory effect of cell viability was enhanced with an increased realgar dose and incubation time. The viability rate decreased to $69.67 \pm 2.63 \%$ when the treatment time increased to $72 \mathrm{~h}$. There was a significant difference between the two $2 \mu \mathrm{M}$ realgar-treated groups $(\mathrm{P}<0.01)$. In addition, $10.59 \pm 1.61 \%$ cells remained viable when exposed to $20 \mu \mathrm{M}$ realgar for $24 \mathrm{~h}$ $(\mathrm{P}<0.01)$. The $\mathrm{IC}_{50}$ at 24,48 and $72 \mathrm{~h}$ was $7.998,6.380$ and $6.219 \mu \mathrm{M}$, respectively.

Realgar inhibits the proliferation of MEC-1 cells. BrdU cell proliferation ELISA was performed to investigate whether realgar suppressed the proliferation of MEC-1 cells. The inhibition of the proliferation of MEC-1 cells occurred in a concentration- and time-dependent manner (Fig. 2). Treatment of MEC- 1 cells with realgar at 2, 6 and $10 \mu \mathrm{M}$ reduced the proliferation of MEC-1 cells by 5.68, 42.78 and $58.08 \%$ following $24 \mathrm{~h}$ and $30.90,60.72$ and $70.09 \%$ following $48 \mathrm{~h}$, respectively.

Realgar induces apoptosis of MEC-1 cells. The apoptotic effect of realgar on MEC-1 cells was determined by annexin V-FITC/PI dual staining, followed by flow cytometry analysis. As shown in Fig. 3, apoptosis of MEC-1 cells was induced by realgar in a dose- and time-dependent manner. Following treatment with $2 \mu \mathrm{M}$ realgar for $24 \mathrm{~h}$, the percentage of apoptotic cells increased between $6.78 \pm 0.60$ and $9.26 \pm 1.25 \%$ $(\mathrm{P}<0.05)$. With an increase in incubation time or concentration of realgar, the induction of apoptosis was significantly enhanced. Percentages of apoptotic cells, following incubation with $2 \mu \mathrm{M}$ realgar for $48 \mathrm{~h}$ and $6 \mu \mathrm{M}$ for $24 \mathrm{~h}$, were $14.44 \pm 1.54$ $(\mathrm{P}<0.01)$ and $36.09 \pm 2.48 \%(\mathrm{P}<0.01)$, respectively.

Realgar upregulates $m R N A$ levels of BAX while downregulating $m R N A$ levels of $c-M y c$. To further investigate whether realgar-induced apoptosis was dependent on the mitochondrial apoptosis pathway, the effect of realgar on the mRNA levels of $B A X, B c l-x L, c-M y c$ and $p 21$ genes was measured by quantitative PCR. Following treatment with $6 \mu \mathrm{M}$ realgar for $48 \mathrm{~h}$, mRNA expression of $B A X$ in MEC-1 cells was upregulated almost 2-fold while $c-M y c$ mRNA expression was reduced by more than half (Fig. 4). However, no significant difference in the expression of $B c l-x L$ and $p 21$ was observed between the realgar-treated and untreated MEC-1 cells.

\section{Discussion}

Studies have been conducted on the antineoplastic effect of realgar. Realgar has been shown to have antiproliferative

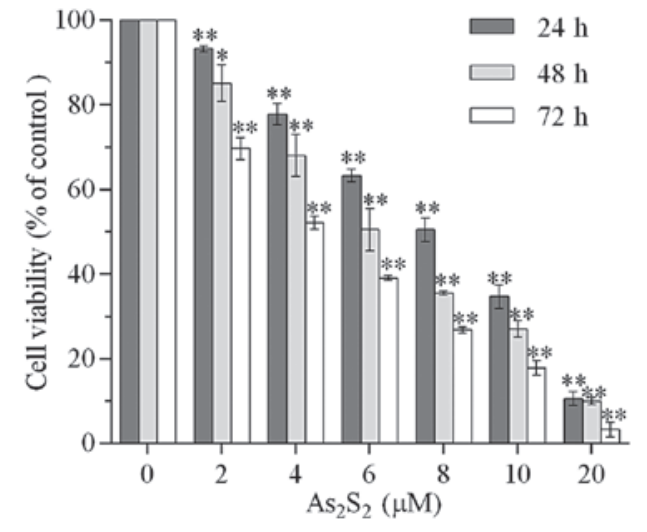

Figure 1. Effect of realgar on the viability of MEC-1 cells. MEC-1 cells were treated with various concentrations of realgar $(0,2,4,6,8,10$ and $20 \mu \mathrm{M})$ for 24,48 and $72 \mathrm{~h}$. WST- 8 assay was used to evaluate cell viability. Data are presented as the percentages relative to the untreated control and as mean $\pm \mathrm{SD}$. ${ }^{*} \mathrm{P}<0.05$ and ${ }^{* *} \mathrm{P}<0.01$, vs. control.

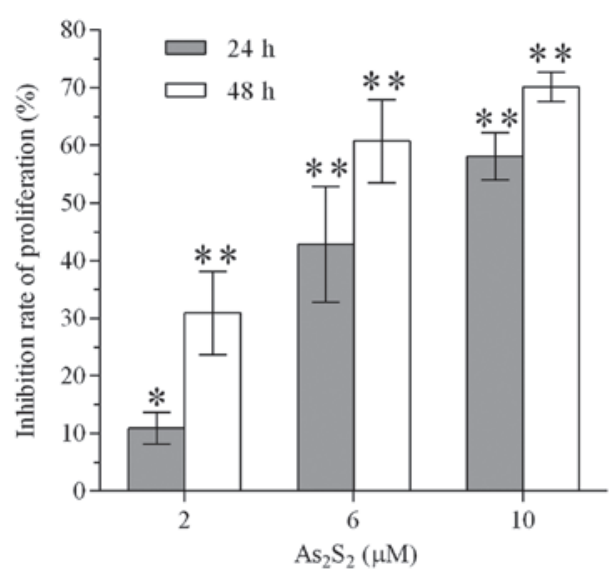

Figure 2. Effect of realgar on the proliferation of MEC-1 cells. MEC-1 cells were incubated with $0,2,6$ and $10 \mu \mathrm{M}$ realgar for 24 and $48 \mathrm{~h}$. BrdU cell proliferation ELISA was performed to measure proliferation. Values are presented as mean $\pm \mathrm{SD}$. ${ }^{*} \mathrm{P}<0.05$ and ${ }^{* *} \mathrm{P}<0.01$, vs. control. BrdU, 5-bromodeoxyuridine.

and pro-apoptotic effects on a number of cancer cell lines, including rat glioma C6 cells, mouse melanoma B16 cells and the cervical cancer cell line SiHa (19-21). More studies on the antineoplastic effect of realgar have been carried out in a few cells types of malignant hematologic diseases. The majority of these studies have focused on promyelocytic leukemia HL-60 cells, APL cell line NB4 and CML cell line K562, as well as peripheral blood or bone marrow cells gained from APL and CML patients. Consequently, considerable success has been achieved. Oxidative stress, membrane toxicity and protein tyrosine kinase may be involved in the process of realgar-induced apoptosis $(14,22)$. Realgar has been reported to induce apoptosis in human histocytic lymphoma U937 cells through caspase, MAPK and mitochondrial pathways $(23,24)$. However, no studies focusing on the effect of realgar on CLL cells have been conducted prior to this study.

CLL is a malignant disease of B lymphocytes, initially recognized as the result of accumulation of rest cells. However, CLL was later found to be a disease of activated monoclonal cells that proliferated in particular microenvironments $(25,26)$. 
A
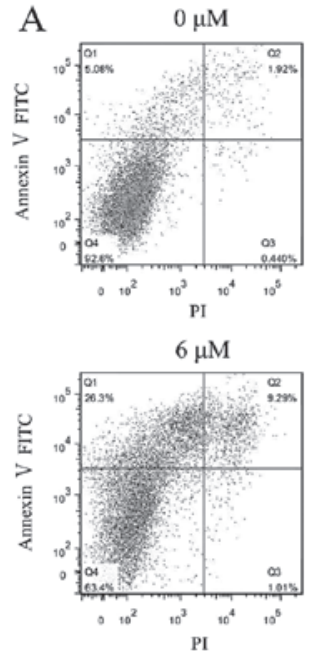

$\mathrm{C}$

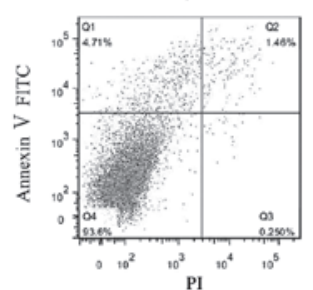

$6 \mu \mathrm{M}$

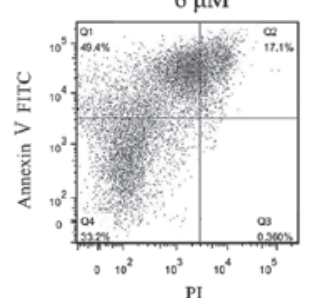

$2 \mu \mathrm{M}$
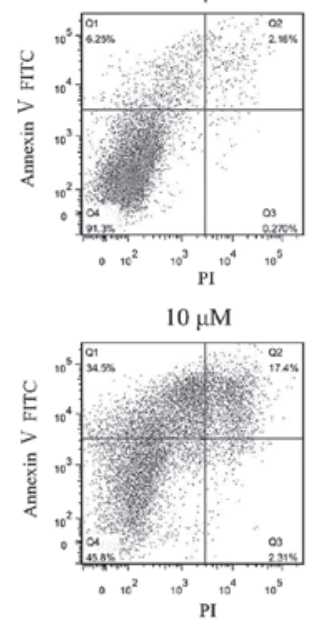

$2 \mu \mathrm{M}$

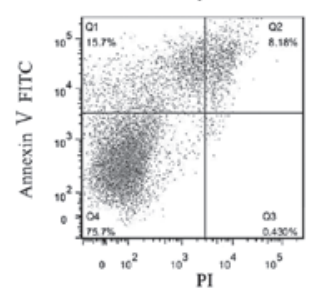

$10 \mu \mathrm{M}$

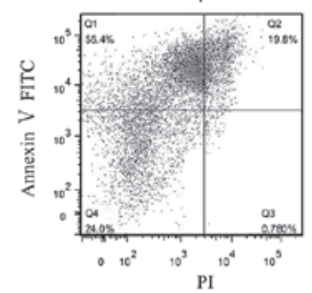

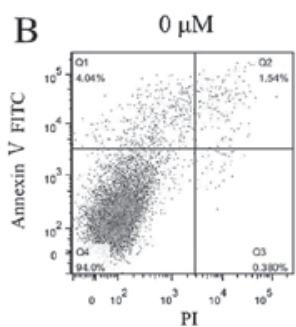
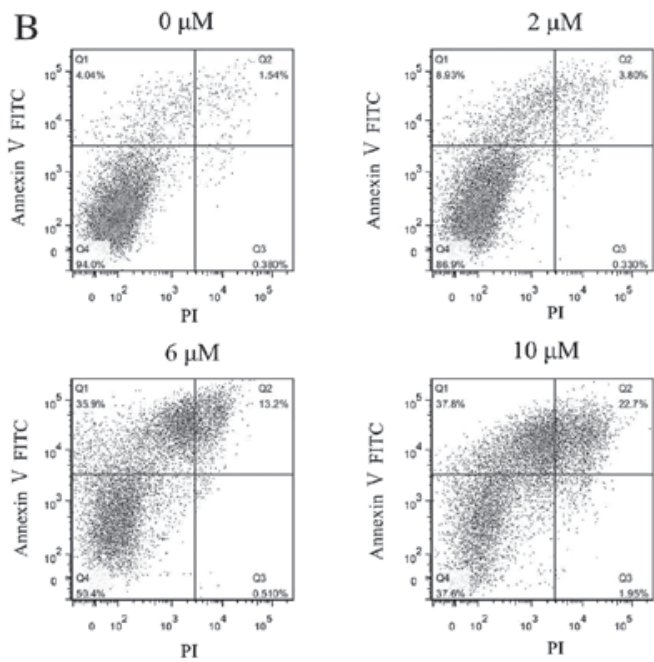

D

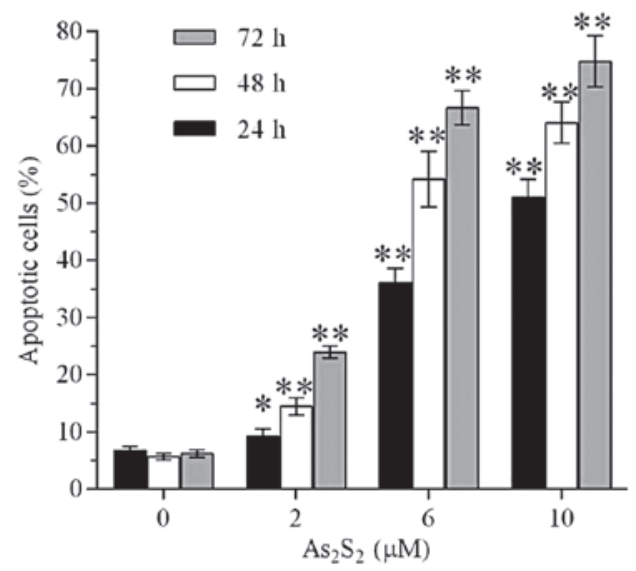

Figure 3. Effect of realgar on the apoptosis of MEC-1 cells. MEC-1 cells were incubated with realgar at concentrations of $0,2,6$ and $10 \mu \mathrm{M}$ for (A) 24, (B) 48 and (C) $72 \mathrm{~h}$. The apoptotic rate was determined by annexin V-FITC/PI dual staining followed by flow cytometry. The left upper quadrant of the lower panel shows the percentage of viable cells (annexin V-FITC- and PI-negative), the left quadrant shows the percentage of early apoptotic cells (annexin V-FITC-positive and PI-negative) and the upper right quadrant indicates the percentage of late apoptotic cells (annexin V-FITC- and PI-positive). (D) Realgar induced apoptosis of MEC-1 cells in a dose- and time-dependent manner. Values are presented as mean \pm SD. ${ }^{*} \mathrm{P}<0.05$ and ${ }^{* *} \mathrm{P}<0.01$, vs. control. FITC, fluoroscein isothiocyanate; PI, propidium iodide.

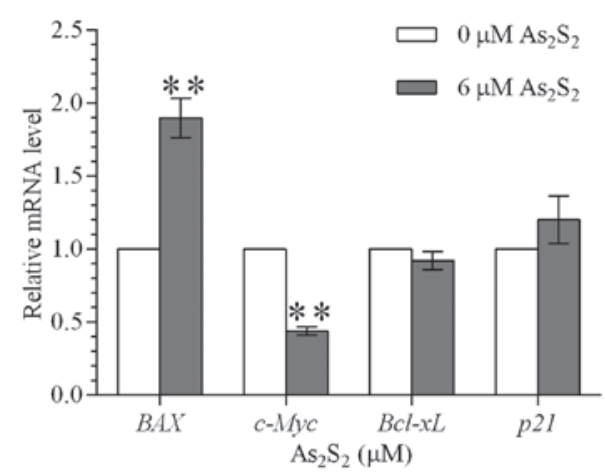

Figure 4. Effect of realgar on the transcriptional levels of $B A X, B c l-x L, c-M y c$ and $p 21$ genes in MEC-1 cells. Relative mRNA levels of $B A X, B c l-x L, c-M y c$ and $p 21$ genes were assessed by quantitative PCR in MEC-1 cells following treatment with 0 and $6 \mu \mathrm{M}$ realgar for $48 \mathrm{~h}$. The $2^{-\Delta \Delta \mathrm{Ct}}$ method was used to calculate the relative mRNA expression to the internal control (actin). mRNA expression of $B A X$ in MEC-1 cells was upregulated, whereas c-Myc mRNA expression was downregulated. Values are presented as mean $\pm \mathrm{SD}$. ${ }^{*} \mathrm{P}<0.05$ and ${ }^{* *} \mathrm{P}<0.01$, vs. control. $B A X$, BCL2-associated $\mathrm{X}$ protein; $B c l-x L$, BCL2-like 1; $c$ - Myc, v-myc myelocytomatosis viral oncogene homolog (avian); p21, cyclin-dependent kinase inhibitor $1 \mathrm{~A}$; PCR, polymerase chain reaction.
The molecular mechanism leading to the imbalance between apoptosis and proliferation has attracted considerable attention and associated pathways have been explored widely in order to identify new therapies targeted to cure CLL. In the present study, arsenic compound realgar was used to dispose MEC-1 cells. The MEC-1 cell line was established from the peripheral blood of a CLL patient in prolymphocytoid transformation (27). Several cytogenetic aberrations were detected, including del(17)(p11.2pter) (27). It was found that realgar, not only suppressed viability and proliferation, but also induced apoptosis of MEC-1 cells.

Further investigations were performed analyzing the effect various doses and incubation times had on MEC-1 cells. Following exposure to various concentrations of realgar for different time periods, cell viability and proliferation were inhibited in MEC-1 cells in a dose- and time-dependent manner. The effect of realgar on apoptosis was also evaluated in MEC-1 cells and found to induce apoptosis in a dose- and time-dependent manner. 
Potential mechanisms involved in the realgar-induced apoptosis were explored. mRNA expression of $B A X$ and $c-M y c$ was upregulated and downregulated, respectively, following realgar treatment. $B A X$ belongs to the $B c l-2$ family of pro-apoptotic genes and is an important member of the mitochondrial apoptosis pathway (28). Protein encoded by the $c-M y c$ gene functions as a transcription factor that participates in significant processes, including cell cycle progression, apoptosis and cell transformation. Changes in mRNA expression levels of $B A X$ and $c-M y c$ indicated that realgar-induced apoptosis of MEC-1 cells may be dependent on the mitochondrial pathway.

In summary, the inhibitory effect of realgar on the CLL cell line, to the best of our knowledge, was explored for the first time. Based on the findings of the present study, it may be concluded that realgar inhibited viability and proliferation and induced apoptosis of MEC-1 cells in a dose- and time-dependent manner. This phenomenon may depend on the mitochondrial apoptosis pathway, as the upregulation of $B A X$ expression and downregulation of $c-M y c$ expression was observed in MEC-1 cells following realgar treatment. The results of the present study may be beneficial for the identification of a new target therapy for CLL. In addition, more studies are required to explore the detailed mechanism involved in the process.

\section{Acknowledgements}

The study was supported by grants from the National Natural Science Foundation (no.81270598), Natural Science Foundations of Shandong Province (nos. Y2007C053, 2009ZRB14176 and ZR2012HZ003), Technology Development Projects of Shandong Province (nos. 2007GG10 and 2010GSF10250) and the Program of Shandong Medical Leading Talent and Taishan Scholar Foundation of Shandong Province.

\section{References}

1. Man S, Gao W, Wei C and Liu C: Anticancer drugs from traditional toxic Chinese medicines. Phytother Res 26: 1449-1465, 2012.

2. Soignet SL, Maslak P, Wang ZG, et al: Complete remission after treatment of acute promyelocytic leukemia with arsenic trioxide. N Engl J Med 339: 1341-1348, 1998.

3. Lu J, Chew EH and Holmgren A: Targeting thioredoxin reductase is a basis for cancer therapy by arsenic trioxide. Proc Natl Acad Sci USA 104: 12288-12293, 2007.

4. Hu J, Liu YF, Wu CF, et al: Long-term efficacy and safety of all-trans retinoic acid/arsenic trioxide-based therapy in newly diagnosed acute promyelocytic leukemia. Proc Natl Acad Sci USA 106: 3342-3347, 2009.

5. Kim J, Lee JJ, Kim J, Gardner D and Beachy PA: Arsenic antagonizes the Hedgehog pathway by preventing ciliary accumulation and reducing stability of the Gli2 transcriptional effector. Proc Natl Acad Sci USA 107: 13432-13437, 2010.

6. Zhang XW, Yan XJ, Zhou ZR, et al: Arsenic trioxide controls the fate of the PML-RARalpha oncoprotein by directly binding PML. Science 328: 240-243, 2010.

7. Mahieux R, Pise-Masison C, Gessain A, et al: Arsenic trioxide induces apoptosis in human T-cell leukemia virus type 1- and type 2-infected cells by a caspase-3-dependent mechanism involving Bcl-2 cleavage. Blood 98: 3762-3769, 2001.
8. Bae-Jump VL, Zhou C, Boggess JF and Gehrig PA: Arsenic trioxide $\left(\mathrm{As}_{2} \mathrm{O}_{3}\right)$ inhibits expression of estrogen receptor-alpha through regulation of the mitogen-activated protein kinase (MAPK) pathway in endometrial cancer cells. Reprod Sci 15: 1011-1017, 2008.

9. Kang YH and Lee SJ: The role of p38 MAPK and JNK in Arsenic trioxide-induced mitochondrial cell death in human cervical cancer cells. J Cell Physiol 217: 23-33, 2008.

10. Ahn RW, Chen F, Chen H, et al: A novel nanoparticulate formulation of arsenic trioxide with enhanced therapeutic efficacy in a murine model of breast cancer. Clin Cancer Res 16: 3607-3617, 2010.

11. Raju GP: Arsenic: a potentially useful poison for Hedgehog-driven cancers. J Clin Invest 121: 14-16, 2011.

12. Hu XM, Liu F and Ma R: Application and assessment of Chinese arsenic drugs in treating malignant hematopathy in China. Chin J Integr Med 16: 368-377, 2010.

13. Xiang Y, Wang XB, Sun SJ, et al: Compound huangdai tablet as induction therapy for 193 patients with acute promyelocytic leukemia. Zhonghua Xue Ye Xue Za Zhi 30: 440-442, 2009 (In Chinese).

14. Li JE, Wu WL, Wang ZY and Sun GL: Apoptotic effect of $\mathrm{As}_{2} \mathrm{~S}_{2}$ on K562 cells and its mechanism. Acta Pharmacol Sin 23: 991-996, 2002.

15. Mao JH, Sun XY, Liu JX, et al: $\mathrm{As}_{4} \mathrm{~S}_{4}$ targets RING-type E3 ligase c-CBL to induce degradation of BCR-ABL in chronic myelogenous leukemia. Proc Natl Acad Sci USA 107: 21683-21688, 2010.

16. Bairey O, Vanichkin A and Shpilberg O: Arsenic-trioxide-induced apoptosis of chronic lymphocytic leukemia cells. Int J Lab Hematol 32 (1 Pt 1): e77-e85, 2010.

17. Redondo-Muñoz J, Escobar-Díaz E, Hernández Del Cerro M, et al: Induction of B-chronic lymphocytic leukemia cell apoptosis by arsenic trioxide involves suppression of the phosphoinositide 3-kinase/Akt survival pathway via c-jun- $\mathrm{NH}_{2}$ terminal kinase activation and PTEN upregulation. Clin Cancer Res 16: 4382-4391, 2010.

18. Yin T, Wu YL, Sun HP, et al: Combined effects of $\mathrm{As}_{4} \mathrm{~S}_{4}$ and imatinib on chronic myeloid leukemia cells and BCR-ABL oncoprotein. Blood 104: 4219-4225, 2004.

19. Zhao QH, Zhang Y, Liu Y, et al: Anticancer effect of realgar nanoparticles on mouse melanoma skin cancer in vivo via transdermal drug delivery. Med Oncol 27: 203-212, 2010.

20. An YL, Nie F, Wang ZY and Zhang DS: Preparation and characterization of realgar nanoparticles and their inhibitory effect on rat glioma cells. Int J Nanomedicine 6: 3187-3194, 2011.

21. Cheng YX, Liu R, Wang Q, et al: Realgar-induced apoptosis of cervical cancer cell line Siha via cytochrome $c$ release and caspase-3 and caspase-9 activation. Chin J Integr Med 18: 359-365, 2012.

22. Ye HQ, Gan L, Yang XL and Xu HB: Membrane-associated cytotoxicity induced by realgar in promyelocytic leukemia HL-60 cells. J Ethnopharmacol 103: 366-371, 2006.

23. Wang XB, Gao HY, Hou BL, Huang J, Xi RG and Wu LJ: Nanoparticle realgar powders induce apoptosis in U937 cells through caspase MAPK and mitochondrial pathways. Arch Pharm Res 30: 653-658, 2007.

24. Xi RG, Huang J, Li D, Wang XB and Wu LJ: Roles of PI3-K/Akt pathways in nanoparticle realgar powders-induced apoptosis in U937 cells. Acta Pharmacol Sin 29: 355-363, 2008.

25. Klein U and Dalla-Favera R: New insights into the pathogenesis of chronic lymphocytic leukemia. Semin Cancer Biol 20: 377-383, 2010

26. Damle RN, Calissano C and Chiorazzi N: Chronic lymphocytic leukaemia: a disease of activated monoclonal B cells. Best Pract Res Clin Haematol 23: 33-45, 2010.

27. Stacchini A, Aragno M, Vallario A, et al: MEC1 and MEC2: two new cell lines derived from B-chronic lymphocytic leukaemia in prolymphocytoid transformation. Leuk Res 23: 127-136, 1999.

28. Buggins AG and Pepper CJ: The role of Bcl-2 family proteins in chronic lymphocytic leukaemia. Leuk Res 34: 837-842, 2010. 